\title{
A Study on Dual-band Microstrip Rectangular Patch Antenna for Wi-Fi
}

\author{
Rabnawaz Sarmad Uqaili ${ }^{1}$, Junaid Ahmed Uqaili ${ }^{1,}$, Sidrish Zahra $^{2}$, Faraz Bashir Soomro ${ }^{3}$, Ali Akbar ${ }^{4}$ \\ ${ }^{1}$ Beijing University of Posts and Telecommunications, Beijing, China \\ ${ }^{2}$ University of Electronic Science and Technology of China, Chengdu, China \\ ${ }^{3}$ Mehran University of Engineering and Technology, Jamshoro, Sindh, Pakistan \\ ${ }^{4}$ Iqra University, Karachi, Sindh, Pakistan \\ Received 15 March 2020; received in revised form 05 June 2020; accepted 14 August 2020
}

DOI: https://doi.org/10.46604/peti.2020.6266

\begin{abstract}
This paper presents the design of a dual-band microstrip patch antenna for Wi-Fi that operates at $2.5 \mathrm{GHz}$ and $5.8 \mathrm{GHz}$. The antenna contains a rectangular patch with two rectangular slots. The first slot is incorporated in the patch while the second slot is incorporated in the ground plane. The antenna is based on a microstrip fed rectangular patch printed on the FR-4 epoxy substrate with a dielectric constant of 4.4 and a thickness of $1.6 \mathrm{~mm}$ with patch size $24 \mathrm{~mm} \times 21 \mathrm{~mm}$. The simulated result shows that the realized antenna successfully works on dual-band and subsequently achieves a bandwidth of $100 \mathrm{MHz}$ and $200 \mathrm{MHz}$ as well as the return loss about $-29.9 \mathrm{~dB}$ and $-15.16 \mathrm{~dB}$ for $2.5 \mathrm{GHz}$ and $5.8 \mathrm{GHz}$ respectively. A stable omnidirectional radiation pattern is observed in the operating frequency bands. The antenna meets the required specifications for 802.11 WLAN standards.
\end{abstract}

Keywords: antennas, microstrip patch, dual-band, Wi-Fi

\section{Introduction}

There are some emerging challenges, along with the rapid development of applications in wireless communication. To meet the requirement of a suitable antenna has become a big challenge in wireless communication. The microstrip patch antenna is very suitable for wireless applications because of its simple design, various shapes, ease of installation, and flexibility with Integrated Microwave and Millimeter-wave Circuits (MMIC) [1-3]. The essential feature of the microstrip patch antenna consists of four parts: a very flat metallic region usually referred to as the patch, a dielectric substrate, a ground plane normally much larger than the patch, and a feed supplying the power element [4].

Typically, a microstrip patch antenna radiates in a single frequency band. However, antennas are requiring in modern wireless communications that can operate in multi-bands such as 2.4/5.2/5.8 GHz for WLAN [5-6]. Multi-band operations can be accomplished by the simultaneous use of multiple antennas, which increases the cost and complexity of the system. Besides, the use of multiple antennas can cause problems of coupling, which can reduce the efficiency and performance of the antennas [7]. Dual-band microstrip patch antennas have become an active research topic, which aims to address the key limitations including low gain, narrow bandwidth, low efficiency, and low power handling capabilities. Similarly, several dual-band antennas were presented to cover 2.4/5.2/5.8 GHz for WLAN applications [8-9].

The research of microstrip antenna mainly focuses on the small size, wideband, multi-polarization, multi-band, and high gain. Many antennas have been improved to incorporate several communication standards into one system that fulfills the

* Corresponding author. E-mail address: uqaili_junaid@yahoo.com

Tel.: +86-18401639092/+92-3223118747 
growing demand for modern portable wireless communication devices. For this reason, several types of antenna designs have been proposed [10-18]. In [10], the authors have presented the design of low-profile coplanar waveguide (CPW) fed compact meandered patch antenna for dual-band operation. The presented antenna operates at $2 \mathrm{GHz}$ and $5.32 \mathrm{GHz}$, respectively. In [11], the design of the dual-band microstrip patch antenna is presented for $2.4 \mathrm{GHz}$ and $3.6 \mathrm{GHz}$. In [12], the authors have introduced a MIMO dual-band antenna for WLAN communication. In [13], a single feed dual-band WLAN microstrip patch antenna is presented for $2.4 \mathrm{GHz}$ and $5 \mathrm{GHz}$. The dimension of the designed antenna is $56 \times 46.1 \times 4.3 \mathrm{~mm}^{3}$.

In [14], a miniaturized dual-band patch antenna is presented by using the alumina $\left(\mathrm{Al}_{2} \mathrm{O}_{3}\right.$ ceramic) substrate at a height of $4 \mathrm{~mm}$ from the ground plane. The antenna is designed to operate at $2.45 \mathrm{GHz}$ and $4.96 \mathrm{GHz}$. In [15], a compact planar dual-band antenna for WLAN applications is presented. The report antenna is designed to operate at $2.4 \mathrm{GHz}$ and $5.5 \mathrm{GHz}$. In [16], a single band $\mathrm{T}$ shaped microstrip patch antenna is presented for wireless local area network (WLAN) applications. In [17], the authors have presented a low profile microstrip patch antenna for dual-band operation operating at $1.8 \mathrm{GHz}$ and 2.4 GHz. The dimension of the designed antenna is $56 \times 56 \times 1.6 \mathrm{~mm}^{3}$. In [18], a microstrip patch antenna is proposed by introducing the ground defect technique to achieve the dual-band operation for $2.4 \mathrm{GHz}$ and $5.8 \mathrm{GHz}$. The dimension of the designed antenna is $50 \times 50 \times 1.5 \mathrm{~mm}^{3}$. A dual-band microstrip patch antenna with a right-angle triangular aperture slot introduced in [19] was operated at $1.8 \mathrm{GHz}$ and $2.4 \mathrm{GHz}$. The compact single feed dual-band microstrip patch antenna was suggested for modern wireless communication system applications at $2.4 \mathrm{GHz}$ and $2.6 \mathrm{GHz}$ [20].

However, there are some limitations in the existing work such as these antennas could not deliver a uniform omnidirectional radiation pattern. They cover a multiband frequency band, but there is a limit to achieve broadband characteristics at 5.8 GHz for WLAN with wide antenna size. These antennas are not very compact and hardly achieve the bandwidth requirements of dual-band antennas. Hence, multi-band/dual-band antennas with small size characteristics need to be considered due to high demand. Therefore, the dual-band antenna is intended to be designed in this study.

In this study, we have designed a dual-band microstrip patch antenna of the configuration, $44 \times 41 \mathrm{~mm}$ on a $1.6 \mathrm{~mm}$ thick FR-4 substrate for WLAN applications. The antenna comprises a rectangular patch with two rectangular slots placed on the patch and substrate. The slot placement specifies the antenna operating frequencies, a downlink frequency of $2.5 \mathrm{GHz}$ with the return losses of $-29.9 \mathrm{~dB}$, and an uplink frequency of $5.8 \mathrm{GHz}$ with the return losses of $-15.16 \mathrm{~dB}$. Additionally, the values of VSWR of 1.06 and 1.3 are achieved. The methodology and design of the dual-band antenna, parametric analysis and simulation results for the proposed antenna are discussed.

\section{Design of Dual-Band Antenna}

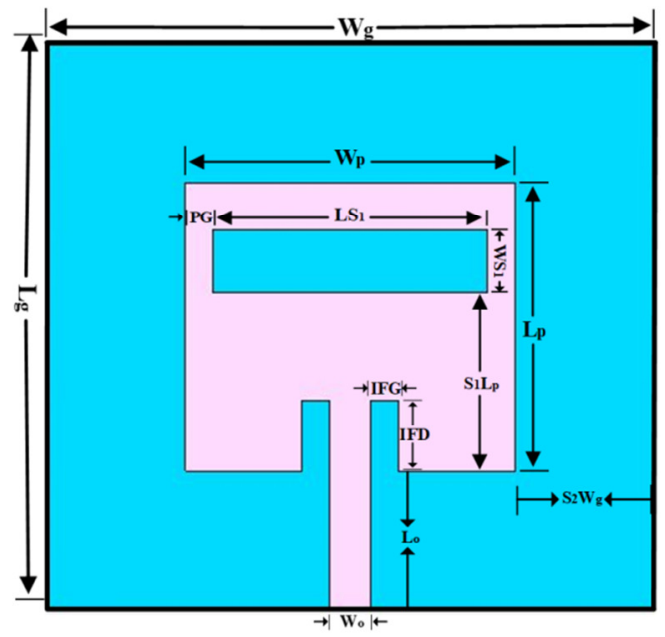

(a) Schematic front-view layout

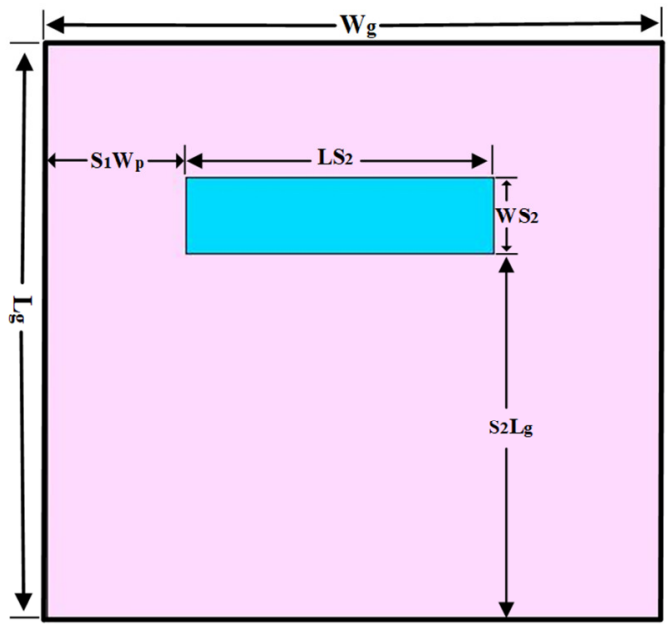

(b) Schematic back-view layout

Fig. 1 The geometry of the proposed dual-band microstrip patch antenna 
The proposed antenna is based on a microstrip fed rectangular patch, which is placed on the FR-4 substrate with a relative dielectric constant $\varepsilon_{r}$ of 4.4 and a loss tangent of $\tan \delta=0.025$, respectively. The substrate has a thickness of $h_{s}=1.6 \mathrm{~mm}$. The patch dimensions and positioning of the rectangular slots are analyzed through the standard antenna formulae and simulation-based optimization techniques in CST Microwave Studio Suite. Fig. 1 shows the rectangular microstrip patch antenna. The antenna normally consists of a rectangular metallic radiating patch of $\mathrm{L}_{\mathrm{p}} \times \mathrm{W}_{\mathrm{p}}$ size incorporated to one side of a dielectric substrate of $\mathrm{L}_{\mathrm{s}} \times \mathrm{W}_{\mathrm{s}}$ size with the relative permittivity $\varepsilon_{\text {reff }}$ and thickness $\mathrm{h}_{\mathrm{s}}$, which has a metallic ground plane on the other side. The radiating patch, which can take any possible shape as well as the feeding network implemented with different techniques, are usually photo-etched on the dielectric substrate.

A rectangular slot of $\mathrm{LS}_{1} \times \mathrm{WS}_{1}$ size is incorporated in the patch while a slot of $\mathrm{LS}_{2} \times \mathrm{WS}_{2}$ size is incorporated in the ground plane. The configuration of the design is demonstrated in Fig. 1. The second resonance is created by the slot technique within the radiating patch as well as a slot in the ground plane. The slot dimensions are carefully varied to allocate both resonances at the desired frequencies. By using the below equations, the starting values for the dimension of the antenna are calculated [21-22], and the final optimized design parameters are obtained by carrying out the parametric analysis to select the proper slot types, sizes, and positions. The patch antenna width $W_{P}$ is calculated by:

$$
W_{P}=\frac{v_{0}}{2 f_{r}} \sqrt{\frac{2}{\varepsilon_{r}+1}}
$$

where $v_{0}$ represents the free space velocity of light, $f_{r}$ represents the resonant frequency, and $\varepsilon_{r}$ represents the relative permittivity.

It is important to consider the effective dielectric constant of the substrate material since the field is not limited to the inside of the substrate material. However, it often propagates in the form of fringing in the air. The effective dielectric constant of substrate material is often smaller than the relative dielectric constant. The patch antenna actual physical length $L_{P}$ is determined by:

$$
L_{P}=L_{e f f}-2 \Delta L
$$

where $L_{e f f}$ is the effective length of patch antenna resulting from fringing fields and can be obtained by:

$$
L_{e f f}=\frac{v_{0}}{2 f_{0} \sqrt{\varepsilon_{r e f f}}}
$$

Because the fringing field dimensions of the patch extend along its length on each end by a distance $\Delta L$, the incremental length $\Delta L$ depends on the effective dielectric constant $\left(\varepsilon_{\text {reff }}\right)$, and the ratio of width to height $W_{P} / h_{s} . \Delta L$ can be obtained by:

$$
\Delta L=0.412 h_{s} \frac{\left(\varepsilon_{\text {reff }}+0.3\right)\left(\frac{W_{p}}{h_{s}}+0.264\right)}{\left(\varepsilon_{\text {reff }}-0.258\right)\left(\frac{W_{p}}{h_{s}}+0.8\right)}
$$

where $\varepsilon_{\text {reff }}$ is the effective dielectric constant on a substrate of the microstrip patch antenna, $h_{s}$ represents the height of the substrate, and $\rho$ represents the radiation coefficient.

$$
\varepsilon_{\text {reff }}=\frac{\varepsilon_{r}+1}{2}+\frac{\varepsilon_{r}-1}{2}\left(1+\frac{12 h}{W_{p}}\right)^{-\frac{1}{2}}
$$




$$
\begin{aligned}
& V S W R=\frac{1+\rho}{1-\rho} \\
& \text { Return loss }=-10 \log \left(\frac{1}{\rho^{2}}\right)
\end{aligned}
$$

The resonant input resistance $R_{\text {in }}$ at a distance $\left(y=y_{0}\right)$ from the edge for the inset feed line is expressed as:

$$
R_{i n}\left(y=y_{0}\right)=R_{i n}(y=0) \cdot \cos ^{2}\left(\frac{\pi}{L_{P}} y_{0}\right)
$$

For the patch antenna, the required value of $R_{\text {in }}\left(y=y_{0}\right)$ should be $50 \mathrm{ohms}$, as the feed line is also of $50 \mathrm{ohms}$. The value of $y_{0}$ is the distance at which the patch antenna has $R_{\text {in }}=50$ ohms. $R_{\text {in }}(y=0)$ is the resonant input resistance at the edge, which can be obtained by:

$$
R_{i n}(y=0)=\frac{1}{2\left(G_{1} \mp G_{12}\right)}
$$

where $G_{1}$ is the self-conducting slots when two radiating slots characterize the microstrip patch antenna, and $G_{12}$ is the mutual conductance between the slots as given by:

$$
\begin{aligned}
& G_{1}= \begin{cases}\frac{1}{90}\left(\frac{W_{P}}{\lambda_{0}}\right)^{2} \quad w \ll \lambda_{0} \\
\frac{1}{120}\left(\frac{W_{P}}{\lambda_{0}}\right)^{2} \quad w \gg \lambda_{0}\end{cases} \\
& G_{12}=\frac{1}{120 \pi^{2}} \int_{0}^{\pi}\left[\frac{\sin \left(\frac{k_{0} W}{2}\right) \cos \theta}{\cos \theta}\right]^{2} j_{0}\left(k_{0} L \sin \theta\right) \sin ^{3} \theta d \theta
\end{aligned}
$$

where $\lambda_{0}$ is the wavelength free-space, $j_{0}$ is the first kind of Bessel zero-order function, and $k_{0}$ is the wavenumber. Compared with self-inductance $G_{1}$, the mutual conductance $G_{12}$ is usually very small. By arranging terms, the width of the microstrip feed line $W_{0}$ for the characteristic resistance of $Z_{c}=50 \mathrm{ohms}$ is calculated as:

$$
Z_{c}=\left\{\begin{array}{cc}
\frac{60}{\sqrt{\varepsilon_{\text {reff }}}} \ln \left(\frac{8 h}{W_{0}}+\frac{W_{0}}{4 h}\right) & \text { if } \frac{W_{0}}{h} \leq 1 \\
\frac{120 \pi}{\sqrt{\varepsilon_{\text {reff }}}}\left[\frac{W_{0}}{h}+1.393+0.667 \ln \left(\frac{W_{0}}{h}+1.44\right)\right] & \text { if } \frac{W_{0}}{h} \geq 1
\end{array}\right.
$$

The junction capacitance is created by the inset feed and patch physical notch which disturbs the frequency of resonance.

$$
g=\frac{v_{0}}{\sqrt{2 \times \varepsilon_{\text {reff }}}} \frac{4.65 \times 10^{-12}}{f_{r}}
$$

\section{Parametric Analysis}

The substrate should be chosen carefully because its height as well as its dielectric constant plays great roles on the antenna performance and its total size. The most suitable substrates for good antenna performance are the thick substrates 
whose dielectric constant is low, which provides better radiation efficiency, higher directivity, and wider bandwidth, at the larger size cost of the element. Table 1 lists the dielectric properties of various substrate materials.

Table 1 Dielectric properties of different substrate materials

\begin{tabular}{|c|c|c|}
\hline Material & Relative Permittivity & Loss Tangent \\
\hline FR-4 & 4.3 & 0.025 \\
\hline Rogers RT 6002 & 2.94 & 0.0012 \\
\hline Rogers RT 5880 & 2.2 & 0.0009 \\
\hline
\end{tabular}

In Fig. 2, the dashed-dot, solid, and short dashed-dot lines correspond to the results of FR-4 with $\sigma=4.3 \times 107 \mathrm{~S} / \mathrm{m}$, Rogers RT 6002 with $\sigma=2.94 \times 107 \mathrm{~S} / \mathrm{m}$, and Rogers RT 5880 with $\sigma=2.2 \times 107 \mathrm{~S} / \mathrm{m}$, respectively. We observe the impact of the various materials on the return loss. When the low permittivity material Rogers RT 5880 is used as a substrate, one resonance is not needed for dual-band operation. By using the Rogers RT 6002, the first resonant is achieved at $3 \mathrm{GHz}$ and the second resonant is achieved at $6.9 \mathrm{GHz}$, which is unwanted. It can be noticed that by using FR-4, the first resonant is achieved at 2.5 $\mathrm{GHz}$ and the second resonant is achieved at $5.8 \mathrm{GHz}$. By analyzing the return loss and required desired frequency bands, FR-4 is selected to design the proposed antenna.

The comparative results for the different values of the patch width on the return loss are shown in Fig. 3. The dashed-dot, solid and short dashed-dot lines correspond to the results of the return loss having the patch width $\mathrm{W}_{\mathrm{p}}=23,24$, and $25 \mathrm{~mm}$ respectively. The other parameters remain unchanged, and the dual-band is observed with the above values of $\mathrm{W}_{\mathrm{p}}$. For the lower band, the return loss is low by using $\mathrm{W}_{\mathrm{p}}=23$ and $25 \mathrm{~mm}$. For the upper band, the resonant is achieved at $6.02 \mathrm{GHz}$ for $\mathrm{W}_{\mathrm{p}}$ $=23 \mathrm{~mm}$ and $5.57 \mathrm{GHz}$ for $\mathrm{W}_{\mathrm{p}}=25 \mathrm{~mm}$. Thus, the optimized values can be deemed as $\mathrm{W}_{\mathrm{p}}=24 \mathrm{~mm}$ to achieve both bands at 2.5 $\mathrm{GHz}$ and $5.8 \mathrm{GHz}$ with the return loss $-29.9 \mathrm{~dB}$ and $-15.16 \mathrm{~dB}$ respectively.

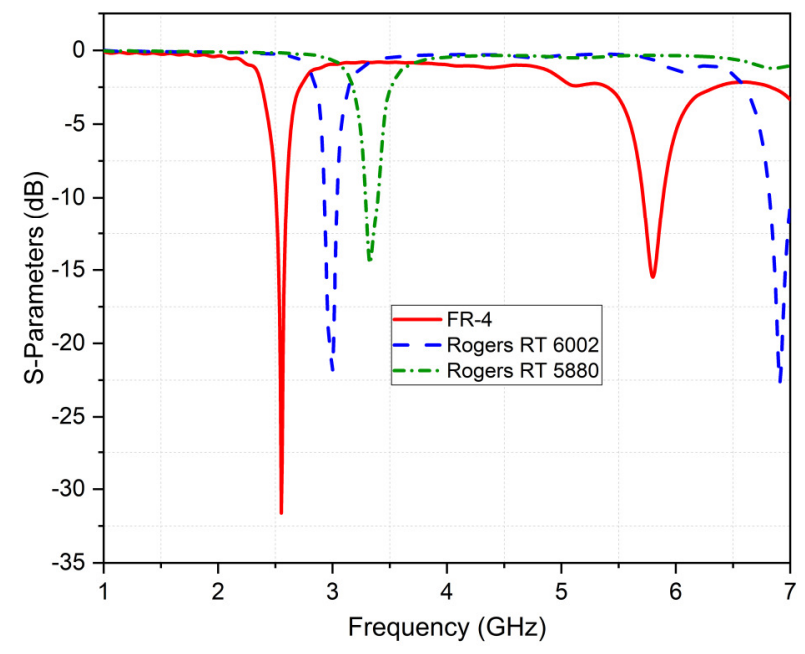

Fig. 2 The simulated return loss $\left(\mathrm{S}_{11}\right)$ for different dielectric materials

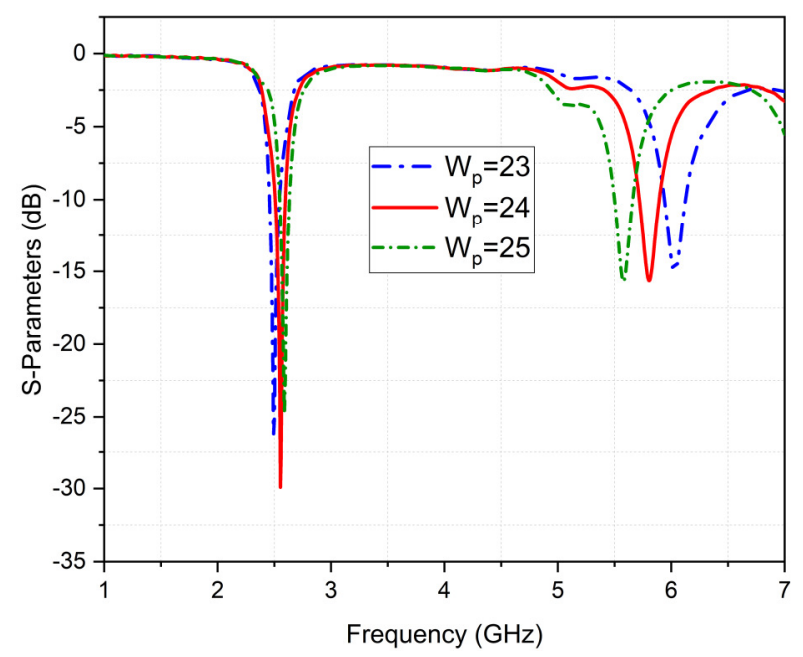

Fig. 3 The influence of width of the patch $\left(\mathrm{W}_{\mathrm{p}}\right)$ on the simulated return loss $\left(\mathrm{S}_{11}\right)$

The comparative results for the different values of the patch length on the return loss are illustrated in Fig. 4. The dashed-dot, solid, and short dashed-dot lines correspond to the results of the return loss having the patch length $\mathrm{L}_{\mathrm{p}}=20,21$, and $22 \mathrm{~mm}$ respectively. The other parameters remain unchanged, and the dual-band is observed with the above values of $\mathrm{L}_{\mathrm{p}}$. It can be seen that as $\mathrm{L}_{\mathrm{p}}$ increases from $20 \mathrm{~mm}$ to $22 \mathrm{~mm}$, the return loss decreases for both bands. For the lower band, the resonant is achieved at $2.8 \mathrm{GHz}$ with $-44.65 \mathrm{~dB}$ return loss for $\mathrm{L}_{\mathrm{p}}=20 \mathrm{~mm}$ and $2.27 \mathrm{GHz}$ with $-14.4 \mathrm{~dB}$ return loss for $\mathrm{L}_{\mathrm{p}}=22 \mathrm{~mm}$. So, the optimized values can be considered as $\mathrm{L}_{\mathrm{p}}=21 \mathrm{~mm}$ to achieve both bands.

Fig. 5 depicts the simulated return loss for the different microstrip feed line $\left(\mathrm{L}_{\mathrm{o}}\right)$ length values. $\mathrm{L}_{\mathrm{o}}$ is an important parameter that plays a part in deciding the desired frequency bands. The dashed-dot, solid, and short dashed-dot lines correspond to the results of return loss having $\mathrm{L}_{\mathrm{o}}=9,10$ and $11 \mathrm{~mm}$ respectively. The other parameters remain unchanged. The 
dual-band is observed by using the above values of $\mathrm{L}_{\mathrm{o}}$. For the lower band, the resonant is accomplished at $2.64 \mathrm{GHz}$ with $-17.28 \mathrm{~dB}$ return loss for $\mathrm{L}_{\mathrm{o}}=9 \mathrm{~mm}$ and $2.34 \mathrm{GHz}$ with $-18.50 \mathrm{~dB}$ return loss for $\mathrm{L}_{\mathrm{o}}=11 \mathrm{~mm}$. Hence, the optimized values can be regarded as $\mathrm{L}_{\mathrm{o}}=10 \mathrm{~mm}$ to achieve both bands.

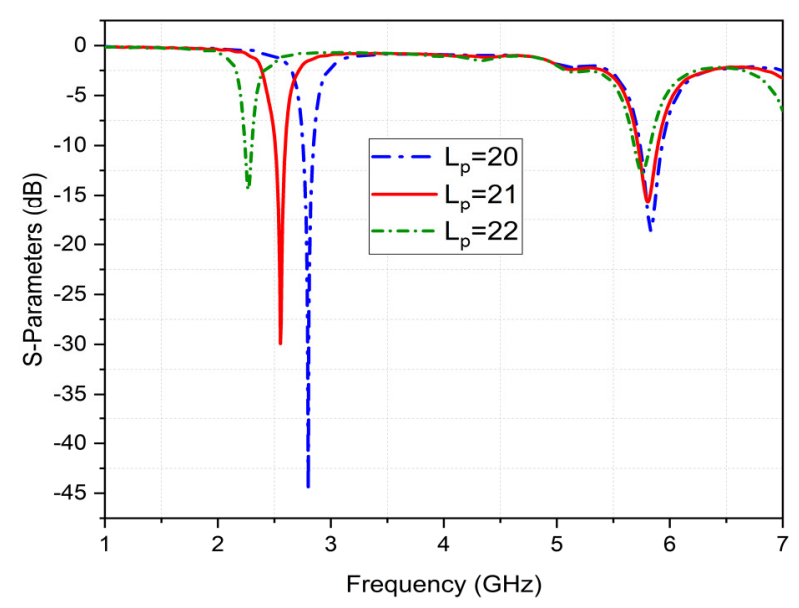

Fig. 4 The influence of length of the patch $\left(\mathrm{L}_{\mathrm{p}}\right)$ on the simulated return loss $\left(\mathrm{S}_{11}\right)$

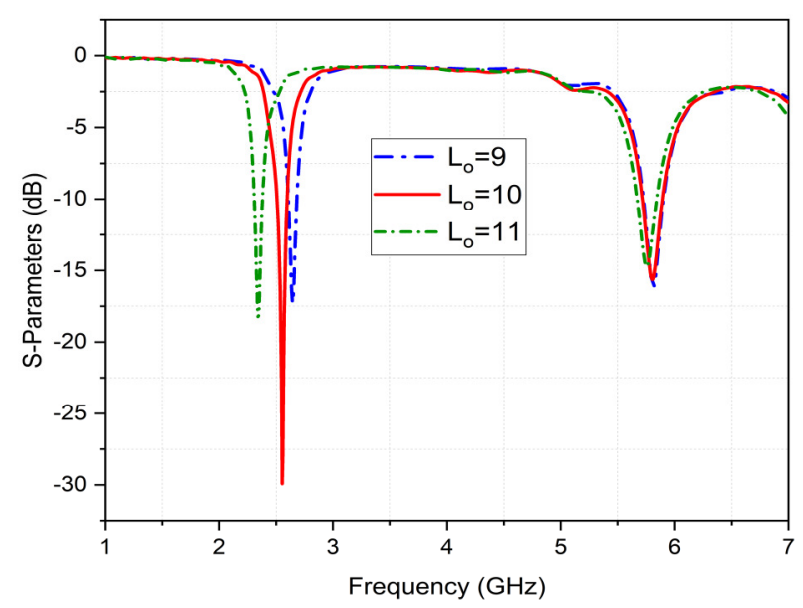

Fig. 5 The influence of length of microstrip feed line $\left(\mathrm{L}_{\mathrm{o}}\right)$ on the simulated return loss $\left(S_{11}\right)$

Fig. 6 indicates the simulated return loss for the different width values of the microstrip feed line $\left(\mathrm{W}_{\mathrm{o}}\right)$. The dashed-dot, solid, and short dashed-dot lines correspond to the results of the return loss having $\mathrm{W}_{\mathrm{o}}=2.5,3$, and 3.5 mm respectively. The other parameters remain unchanged. The dual-band is observed by using the above values of $\mathrm{W}_{\mathrm{o}}$. The $\mathrm{W}_{\mathrm{o}}$ is an important parameter that controls the impedance matching. The optimized value is $\mathrm{W}_{\mathrm{o}}=3 \mathrm{~mm}$ for the appropriate characteristics of both bands.

Fig. 7 depicts the simulated return loss for the different values of the length of slot-1 (LS 1$)$. The dashed-dot, solid, and short dashed-dot lines correspond to the results of the return loss having $\mathrm{LS}_{1}=19,20$, and $21 \mathrm{~mm}$ respectively. The other parameters are unchanged. The dual-band is observed with the above values of $\mathrm{LS}_{1}$. For the lower band, the return loss is high by using $\mathrm{LS}_{1}=19$ and $21 \mathrm{~mm}$. For the upper band, the resonant is attained at $5.7 \mathrm{GHz}$ with $-15.07 \mathrm{~dB}$ return loss for $\mathrm{LS}_{1}=19$ $\mathrm{mm}$ and $5.8 \mathrm{GHz}$ with $-15.96 \mathrm{~dB}$ return loss for $\mathrm{LS}_{1}=21 \mathrm{~mm}$. Therefore, the optimized values can be considered as $\mathrm{LS}_{1}=24$ $\mathrm{mm}$ to achieve both bands at $2.5 \mathrm{GHz}$ and $5.8 \mathrm{GHz}$ with return loss $-29.9 \mathrm{~dB}$ and $-15.16 \mathrm{~dB}$ respectively.

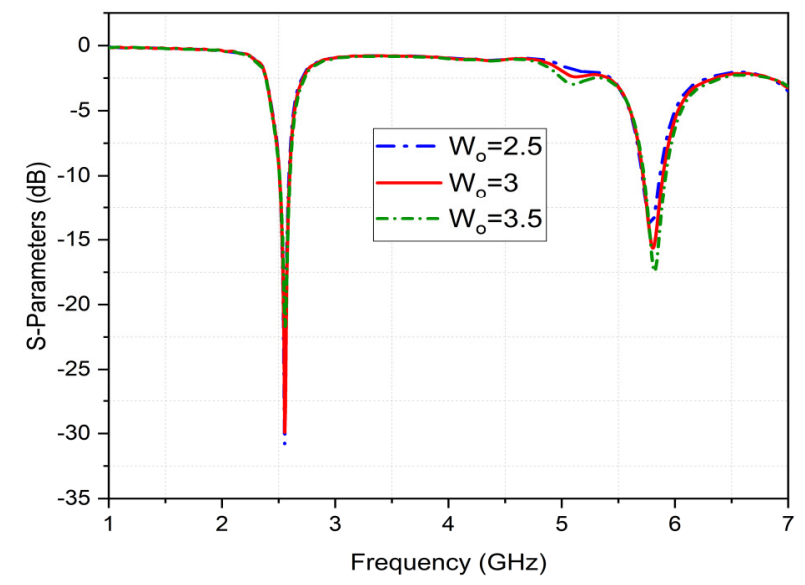

Fig. 6 The influence of width of microstrip feed line $\left(\mathrm{W}_{\mathrm{o}}\right)$ on the simulated return loss $\left(\mathrm{S}_{11}\right)$

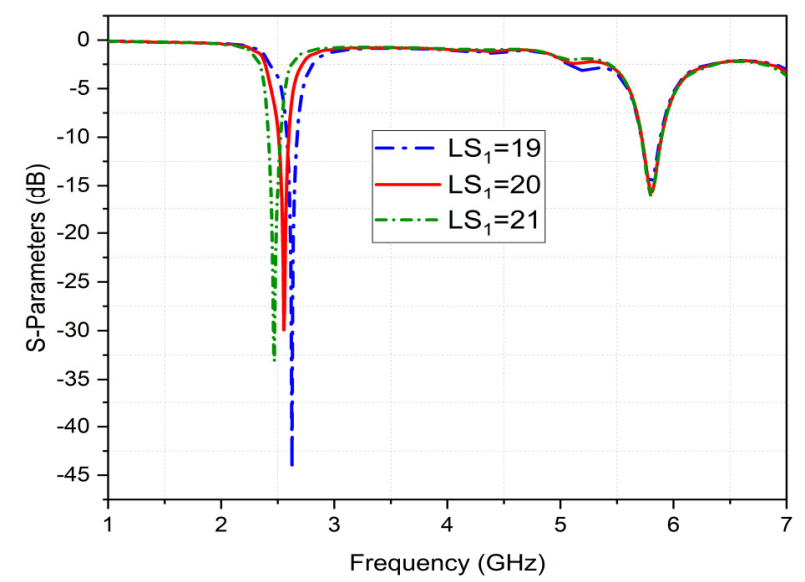

Fig. 7 The influence of length of Slot-1 $\left(\mathrm{LS}_{1}\right)$ on the simulated return loss $\left(\mathrm{S}_{11}\right)$

Fig. 8 indicates the simulated return loss for the different values of the length of slot- $1\left(\mathrm{WS}_{1}\right)$. The dashed-dot, solid, and short dashed-dot lines correspond to the results of return loss having $\mathrm{WS}_{1}=4,4.5$ and $5 \mathrm{~mm}$ respectively. The other parameters are unchanged. The dual-band is observed with the above values of $\mathrm{WS}_{1}$. The optimized values of $\mathrm{WS}_{1}=4.5 \mathrm{~mm}$ are obvious as it is better than the other two values of 4 and $5 \mathrm{~mm}$. 


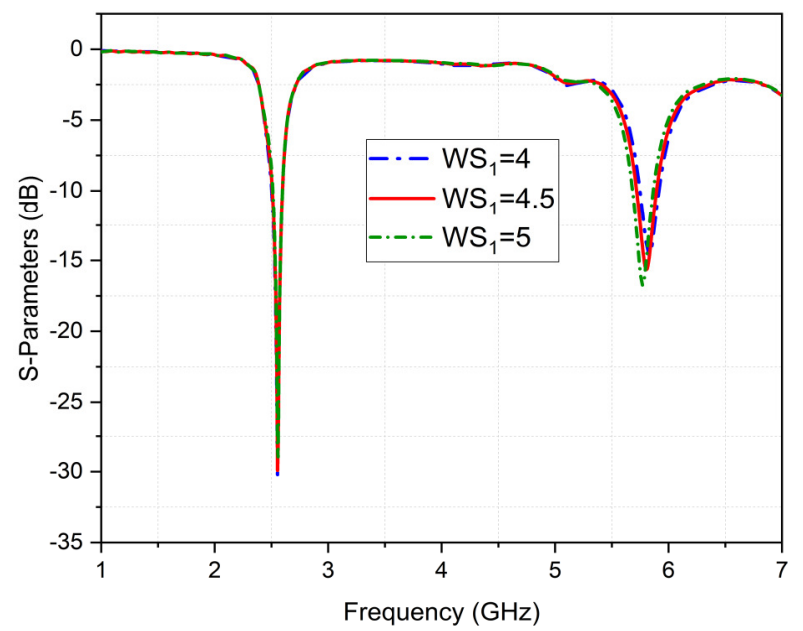

Fig. 8 The influence of width of Slot-1 $\left(\mathrm{WS}_{1}\right)$ on the simulated return loss $\left(\mathrm{S}_{11}\right)$

Fig. 9 indicates the simulated return loss for the different values of the length of slot-2 (LS 2$)$. The dashed-dot, solid, and short dashed-dot lines correspond to the results of return loss having $\mathrm{LS}_{2}=21,22$ and $23 \mathrm{~mm}$ respectively. The other parameters remain unchanged. By using the above values of $\mathrm{LS}_{2}$, the dual-band was observed. The resonant is attained at 2.58 $\mathrm{GHz}$ with $-17.28 \mathrm{~dB}$ return loss for $\mathrm{LS}_{2}=21 \mathrm{~mm}$ and $2.53 \mathrm{GHz}$ with $-15.31 \mathrm{~dB}$ for $\mathrm{LS}_{2}=23 \mathrm{~mm}$ for the lower band. So, the optimized value can be regarded as $\mathrm{LS}_{2}=22 \mathrm{~mm}$ to achieve both bands.

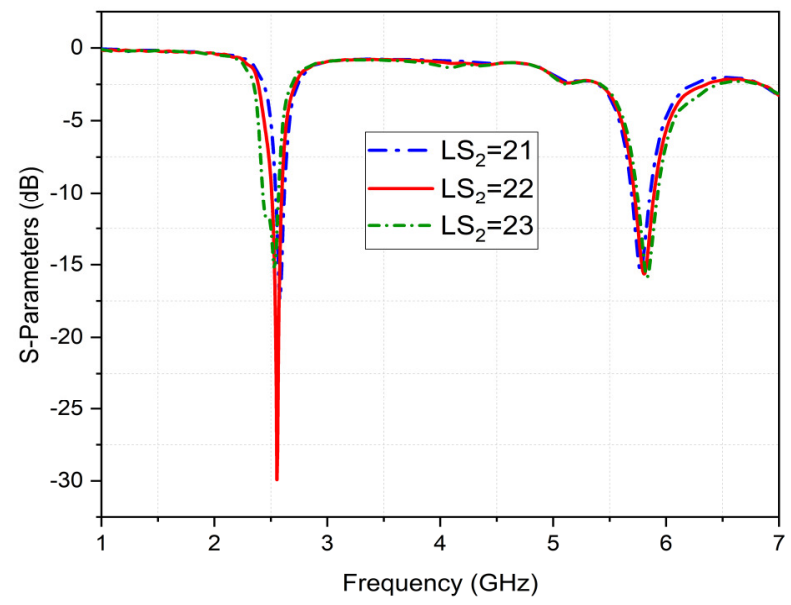

Fig. 9 The influence of length of Slot-2 $\left(\mathrm{LS}_{2}\right)$ on the simulated return loss $\left(\mathrm{S}_{11}\right)$

Table 2 The optimized parameters of the proposed antenna

\begin{tabular}{|c|c|}
\hline Parameters & Values $(\mathrm{mm})$ \\
\hline Length of the ground plane $\left(\mathrm{L}_{\mathrm{g}}\right)$ & 41 \\
\hline Width of the ground plane $\left(\mathrm{W}_{\mathrm{g}}\right)$ & 44 \\
\hline Height of substrate $\left(\mathrm{h}_{\mathrm{s}}\right)$ & 1.6 \\
\hline Patch length $\left(\mathrm{L}_{\mathrm{p}}\right)$ & 21 \\
\hline Patch width $\left(\mathrm{W}_{\mathrm{p}}\right)$ & 24 \\
\hline Length of microstrip feed line $\left(\mathrm{L}_{\mathrm{o}}\right)$ & 10 \\
\hline Width of microstrip feed line $\left(\mathrm{W}_{\mathrm{o}}\right)$ & 3 \\
\hline Inset feed distance $(\mathrm{IFD})$ & 5.2 \\
\hline Inset feed gap $(\mathrm{IFG})$ & 2 \\
\hline Length of Slot1 $\left(\mathrm{LS}_{1}\right)$ & 20 \\
\hline Width of Slot1 $\left.(\mathrm{WS})_{1}\right)$ & 4.5 \\
\hline Length of Slot2 $\left(\mathrm{LS}_{2}\right)$ & 22 \\
\hline Width of Slot2 $\left(\mathrm{WS} \mathrm{S}_{2}\right)$ & 5.5 \\
\hline Distance b/w Slot-1 \& edge of the patch $\left(\mathrm{S}_{1} \mathrm{~L}_{\mathrm{p}}\right)$ & 13 \\
\hline Distance b/w Slot-2 \& edge of the ground plane $\left(\mathrm{S}_{2} \mathrm{~L}_{\mathrm{g}}\right)$ & 26 \\
\hline Distance b/w patch \& edge of the ground plane $(\mathrm{PG})$ & 2.3 \\
\hline Distance b/w Slot-1 \& edge of the patch $\left(\mathrm{S}_{1} \mathrm{~W}_{\mathrm{p}}\right)$ & 12 \\
\hline Distance b/w Slot-2 \& edge of the ground plane $\left(\mathrm{S}_{2} \mathrm{~W}_{\mathrm{g}}\right)$ & 10 \\
\hline
\end{tabular}


Fig. 10 demonstrates the simulated return loss for the different values of the length of slot-2 (WS $)_{2}$. The dashed-dot, solid, and short dashed-dot lines correspond to the results of return loss having $\mathrm{WS}_{2}=5,5.5$ and 6 mm respectively. The other parameters are unchanged. The dual-band was observed by using the above values of $\mathrm{WS}_{2}$. By using $\mathrm{WS}_{2}=5 \mathrm{~mm}$, on the lower band, the return loss is high. However, on the upper band, the return loss is low. By using $\mathrm{WS}_{2}=6 \mathrm{~mm}$, on the lower band, the return loss is low. But, on the upper band, the return loss is high. $\mathrm{WS}_{2}=5.5 \mathrm{~mm}$ is the optimized value. The optimized parameters are summarized in Table 2.

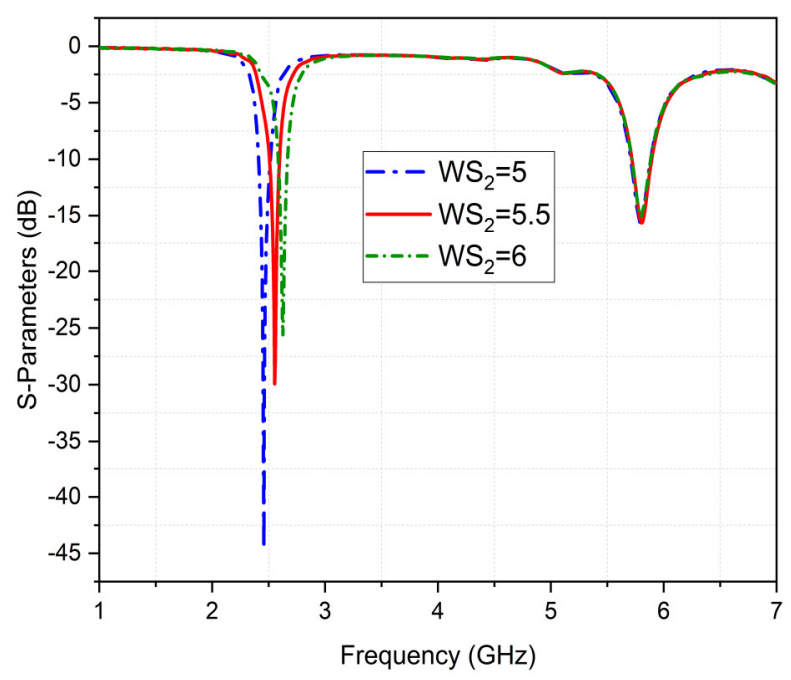

Fig. 10 The influence of length of Slot-1 $\left(\mathrm{WS}_{2}\right)$ on the simulated return loss $\left(\mathrm{S}_{11}\right)$

\section{Simulation Results and Discussions}

The simulated return loss for the proposed antenna is indicated in Fig. 11. The bandwidths of the antennas are determined from the results of $\left|S_{11}\right|>10 \mathrm{~dB}$ and VSWR $<2$. The first band appears between the two resonance frequencies $\mathrm{f}_{1}=2.5 \mathrm{GHz}$ and $\mathrm{f}_{2}=2.6 \mathrm{GHz}$ with about $-29.9 \mathrm{~dB}$ return loss. The second band appears between the two resonance frequencies $\mathrm{f}_{3}=5.7 \mathrm{GHz}$ and $\mathrm{f}_{4}=5.9 \mathrm{GHz}$ with about $-15.16 \mathrm{~dB}$ return loss. When the return loss is less than $-10 \mathrm{~dB}$, the bandwidths are $100 \mathrm{MHz}$ and 200 $\mathrm{MHz}$ which can meet the demand of WLAN in both frequency bands.

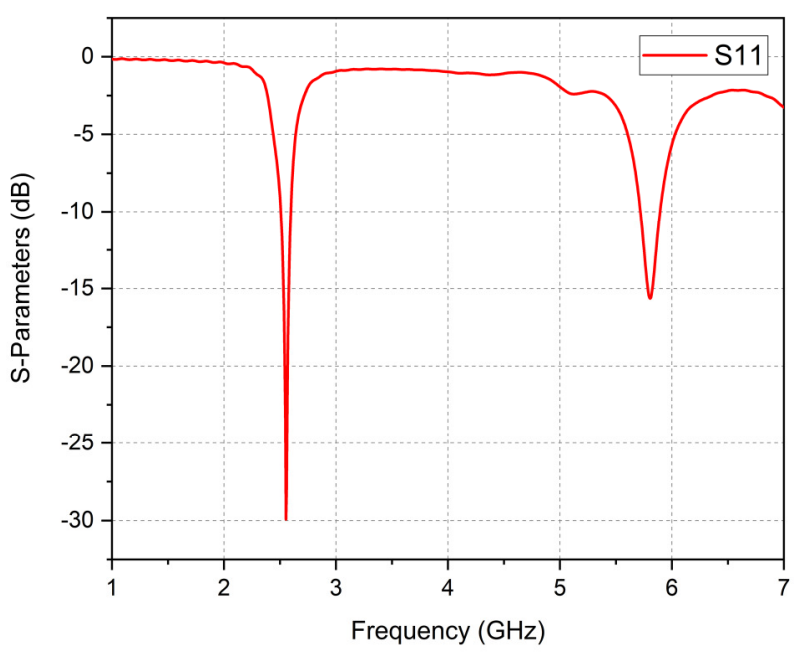

Fig. 11 The return loss $\left(\mathrm{S}_{11}\right)$ of the proposed dual-band microstrip patch antenna

The proposed antenna voltage standing wave ratio (VSWR) simulated curve is illustrated in Fig. 12. The standard values of VSWR are less than 2 for the microstrip patch antenna operating bands. The achieved values of VSWR are 1.06 and 1.3 in the respective operating bands. Hence, the antenna has good transmission characteristics. The simulated gain of the proposed antenna is indicated in Fig. 13. The achieved gain for the lower band is $1.37 \mathrm{~dB}$ and for the upper band is $3.9 \mathrm{~dB}$. 


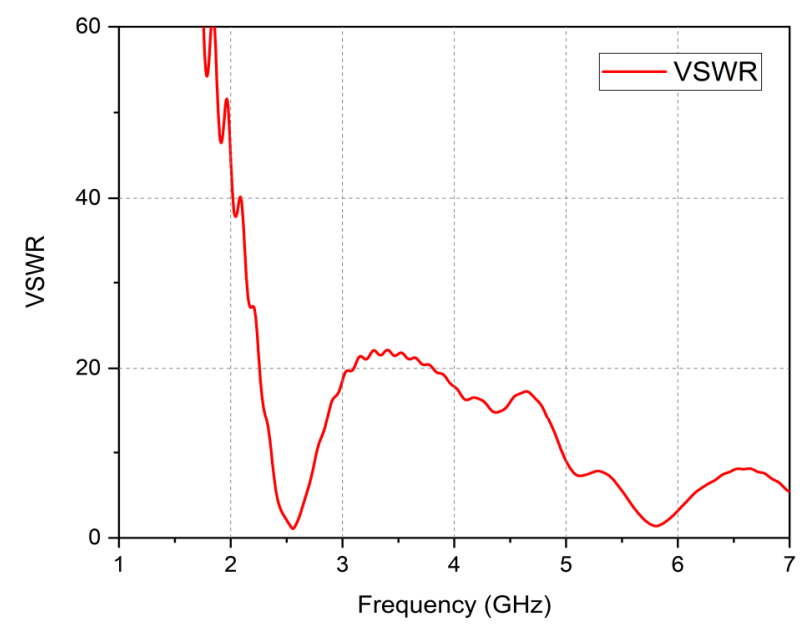

Fig. 12 VSWR of the proposed dual-band microstrip patch antenna

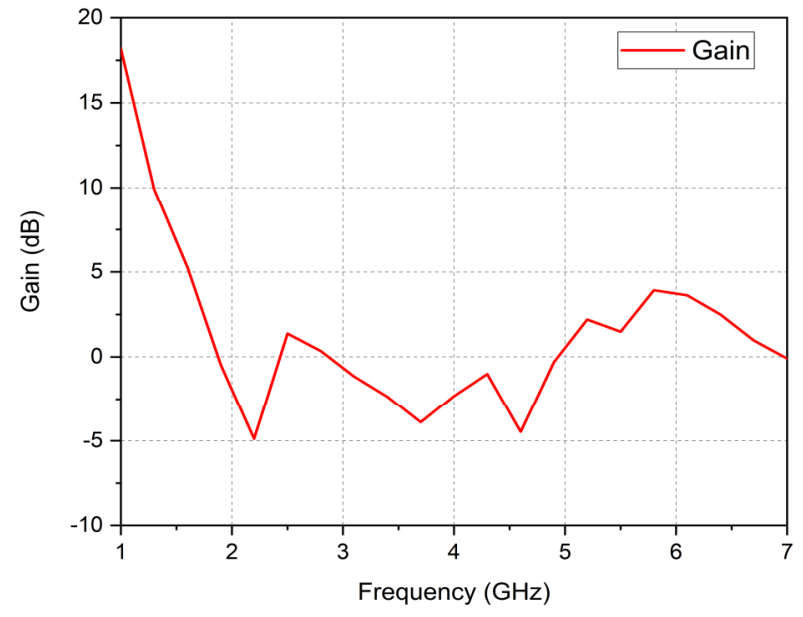

Fig. 13 The simulated gain of the proposed dual-band microstrip patch antenna

Fig. 14 demonstrates the current distribution of the proposed antenna for (a) $2.5 \mathrm{GHz}$ and (b) $5.8 \mathrm{GHz}$. The current vectors are along the patch length, and the feeding line is flowing a significant amount of current. On both operating frequencies bands, the current vectors are omnidirectional. As a result, the excitation for both the lower and upper bands is strong over all parts of the antenna.

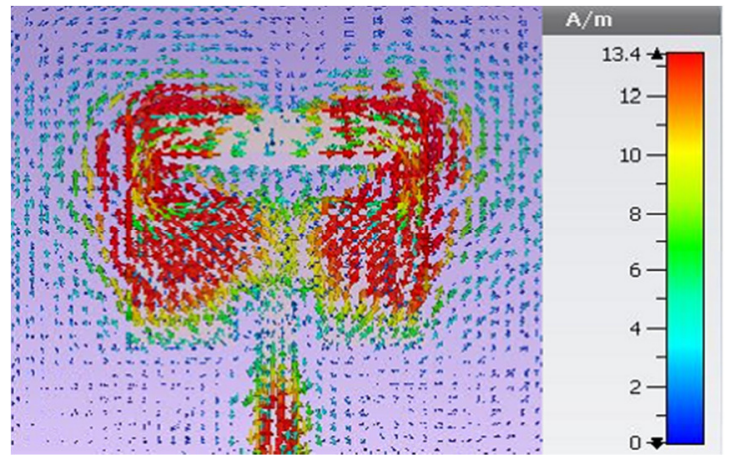

(a) Current Distribution at $2.5 \mathrm{GHz}$

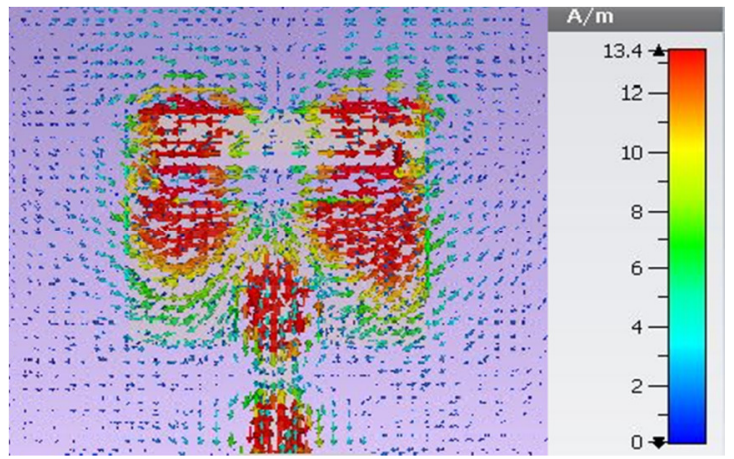

(b) Current Distribution at $5.8 \mathrm{GHz}$

Fig. 14 Surface Current Density Distribution of the proposed dual-band microstrip patch antenna

Fig. 15 depicts the directional pattern of the Far-field antenna. Two-dimensional (2D) radiation patterns represent the co-polarization and cross-polarization at $2.5 \mathrm{GHz}$ and $5.8 \mathrm{GHz}$. The phi $(\varphi)$ and theta $(\theta)$ fields indicate the cross-polar and co-polar components and $5.8 \mathrm{GHz}$, respectively.

In the case of a standard radiation pattern for a microstrip antenna, it is assumed that the effect of cross-polarization would be less than that of co-polarization. Moreover, in the second resonant frequency of $5.8 \mathrm{GHz}$, the cross-polarization effect is high. As the frequency increases cause the effects to enhence, it is clearly described from the radiation pattern. The level of high-frequency cross-polarization is relatively high compared to the lower frequency induced by the patch and ground plane diffractions.

Furthermore, it is observed that by enhancing the slots on the ground plane, the level of this cross-polarization can be reduced. Therefore, the sizes of the patch and ground plane were carefully selected. When some parameters are modified, the resonant frequency shifts.

This also shifts the radiation pattern from symmetric and Omni-directional to bidirectional or another type. By analyzing the radiation pattern, the graph shows one shaped plane " $\infty$ ", and another plane is circular, which shows that the antenna has extraordinary Omni-directional characteristics. 
Farfield Directivity Abs $(\mathrm{Phi}=0)$

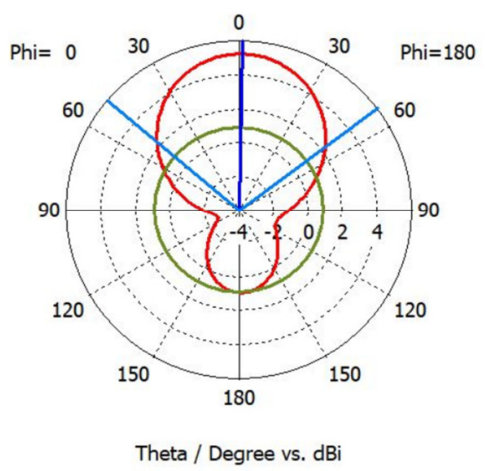

(a) phi $(\varphi)=0$ degree at $2.5 \mathrm{GHz}$

Farfield Directivity Abs (Phi=0)

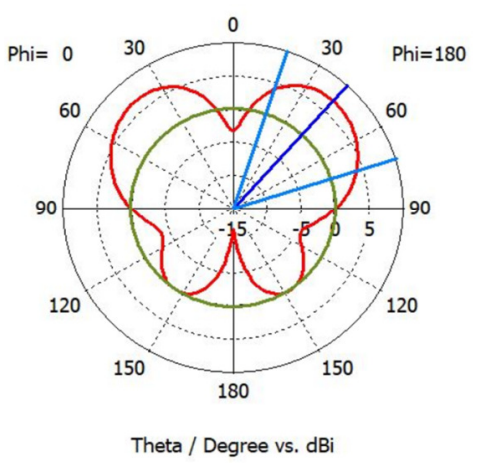

(c) phi $(\varphi)=0$ degree at $5.8 \mathrm{GHz}$

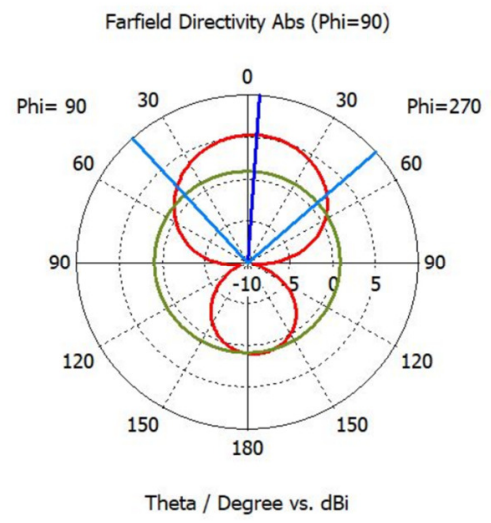

(b) phi $(\varphi)=90$ degree at $2.5 \mathrm{GHz}$

Farfield Directivity Abs (Phi=90)

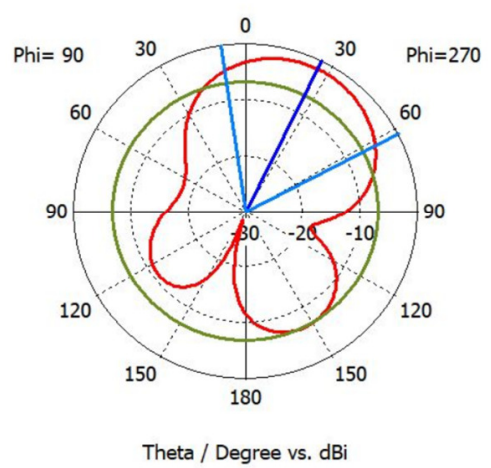

(d) phi $(\varphi)=90$ degree at $5.8 \mathrm{GHz}$

Fig. 15 The simulated 2D radiation pattern of the proposed dual-band microstrip patch antenna

Fig. 16 shows the simulation result for the radiation pattern of the antenna. The radiation pattern is nearly omnidirectional for both bands. The antenna gain is $1.37 \mathrm{~dB}$ and $3.9 \mathrm{~dB}$ for $2.5 \mathrm{GHz}$ and $5.8 \mathrm{GHz}$ respectively, which fulfills the requirement. The simulated results are summarized in Table 3.

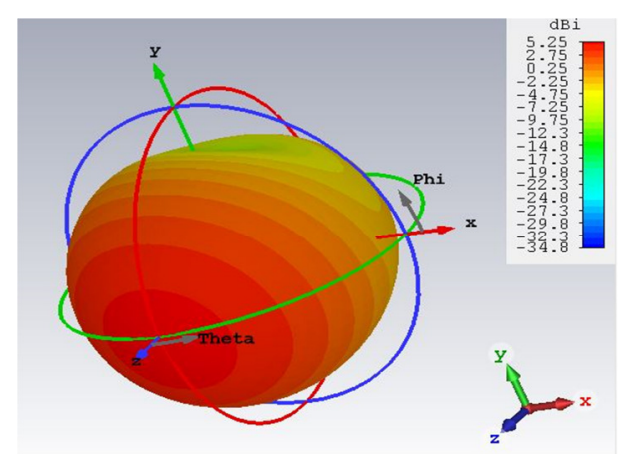

(a) Directivity at $2.5 \mathrm{GHz}$

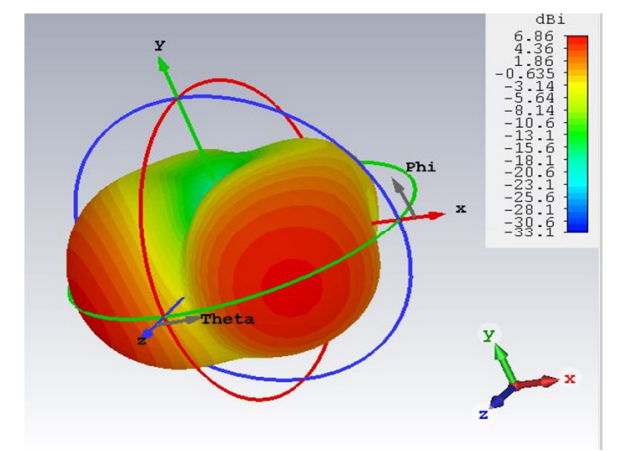

(b) Directivity at $5.8 \mathrm{GHz}$

Fig. 16 The simulated 3D radiation pattern of the proposed dual-band microstrip patch antenna

The performance of the proposed antenna is compared with the other reported antennas in Table 4 . It can be observed that the size of the proposed antenna is compact and suitable for compact wireless devices. The antenna is low cost and simple in fabrication.

Table 3 The summarized simulated results

\begin{tabular}{|c|c|c|}
\hline Parameters & First resonance & Second resonance \\
\hline Frequency $(\mathrm{GHz})$ & 2.5 & 5.8 \\
\hline $\mathrm{S}_{11}(\mathrm{~dB})$ & -29.9 & -15.16 \\
\hline Bandwidth $(\mathrm{GHz})$ & $2.5-2.6=100 \mathrm{MHz}$ & $5.7-5.9=200 \mathrm{MHz}$ \\
\hline VSWR & 1.06 & 1.3 \\
\hline Gain $(\mathrm{dB})$ & 1.37 & 3.9 \\
\hline
\end{tabular}


Table 4 The performance comparison with prior work

\begin{tabular}{|c|c|c|c|}
\hline Ref. & Patch size $\left(\mathrm{mm}^{2}\right)$ & Frequency $(\mathrm{GHz})$ & Fabrication \\
\hline$[13]$ & $39.4 \times 32.9$ & $2.4,5$ & Higher cost and complex \\
\hline$[15]$ & $29 \times 29$ & $2.4,5.5$ & Low cost and simple \\
\hline$[17]$ & $40 \times 29$ & $1.8,2.4$ & Low cost and simple \\
\hline$[11]$ & $38.03 \times 27.13$ & $2.4,3.6$ & Low cost and simple \\
\hline$[18]$ & $25 \times 25$ & $2.4,5.8$ & Low cost and simple \\
\hline This work & $24 \times 21$ & $2.5,5.8$ & Low cost and simple \\
\hline
\end{tabular}

\section{Conclusions}

In this paper, the rectangular microstrip patch antenna is designed for dual-band operation, which operates at $2.5 \mathrm{GHz}$ and 5.8 GHz. The proposed antenna is fully planar, low cost, and small in size. The first band appears at $2.5 \mathrm{GHz}$ with about -29.9 $\mathrm{dB}$ return loss and the second band appears at $5.8 \mathrm{GHz}$ with about $-15.16 \mathrm{~dB}$ return loss. The achieved values of VSWR are 1.06 and 1.3 in the respective operating bands. The simulated results demonstrate the favorable transmission characteristics in both frequency bands. The antennas meet the requirements specifications for 802.11 WLAN and Bluetooth standards. In the future, the designed antenna may be fabricated and tested in a real-time environment.

\section{Conflicts of Interest}

The authors declare no conflict of interest.

\section{References}

[1] G. Kumar and K. P. Ray, Broadband microstrip antennas, USA: Artech House, 1992.

[2] C. A. Balanis, Antenna theory analysis and design, 3rd ed. New York: John Wiley and Sons, 1997.

[3] R. Garg, P. Bhartia, I. J. Bahl, and A. Ittipiboon, Microstrip antenna design handbook, London: Artech House, 2001.

[4] W. L. Stuzman and G. A. Thiele, Antenna theory and design, 2nd ed. New York: John Wiley \& Sons, 1998.

[5] Y. Sung, "Compact dual-band antenna for 2.4/5.2/5.8 GHz WLAN service for laptop computer applications," Microwave and Optical Technology Letters, vol. 57, no. 9, pp. 2207-2213, June 2015.

[6] J. S. Row and Y. J. Huang, "Dual-band dual-polarized antenna for WLAN applications," Microwave and Optical Technology Letters, vol. 60, no.1, pp. 260-265, December 2017.

[7] C. Y. Huang and E. Z. Yu, "A slot-monopole antenna for dual-band WLAN applications," IEEE Antennas and Wireless Propagation Letters, vol. 10, pp. 500-502, May 2011.

[8] C. Y. Pan, T. S. Horng, W. S. Chen, and C. H. Huang, "Dual wideband printed monopole antenna for WLAN/WiMAX applications," IEEE Antennas and Wireless Propagation Letters, vol. 6, pp. 149-151, April 2007.

[9] H. Khodabakhshi and A. Cheldavi, "Irradiation of a six-layered spherical model of human head in the near field of a half-wave dipole antenna," IEEE Transactions on Microwave Theory and Techniques, vol. 58, no. 3, pp. 680-690, March 2010.

[10] W. C. Liu and W. R. Chen, "CPW-fed compact meandered patch antenna for dual-band operation," Electronics Letters, vol. 40, no. 18, pp. 1094-1095, September 2004.

[11] A. D. Dhumale, P. B. Chandole, Chirag, and A. S. Ingole, "Design of dual band microstrip antenna," International Journal of Advance Research, Ideas and Innovations in Technology, vol. 4, no. 2, pp. 1085-1091, April 2018.

[12] J. S. Sun, H. S. Fang, C. S. Chuang, and T. H. Tan, “A compact self-decoupling dual-band MIMO antenna”, Proc. IEEE International Conference on Systems, Man, and Cybernetics (SMC), October 2016, pp. 2386-2390.

[13] F. Meng and S. Sharma, "A single feed dual-band (2.4 GHz/5 GHz) miniaturized patch antenna for wireless local area network (WLAN) communications,” Journal of Electromagnetic Waves and Applications, vol. 30, no. 18, pp. 2390-2401, November 2016.

[14] J. Yang, H. Wang, Z. Lv, and H. Wang, "Design of miniaturized dualband microstrip antenna for WLAN application," Sensors, vol. 16, no.7, p. 983, June 2016.

[15] R. H. Patel and T. K. Upadhyaya, "Compact planar dual band antenna for WLAN application," Progress in Electromagnetics Research, vol. 70, pp. 89-97, September 2017. 
[16] P. Kumar, “A T shaped microstrip antenna for wireless local area network (WLAN) applications," International Conference on Multimedia, Signal Processing and Communication Technologies (IMPACT), November 2017, pp. 147-150.

[17] A. H. Rambe and K. Abdillah, "A low profile rectangular patch microstrip antenna for dual band operation of wireless communication system,” IOP Conference Series: Materials Science and Engineering, vol. 309, March 2018.

[18] M. Mabaso and P. Kumar, "A dual band patch antenna for bluetooth and wireless local area networks applications," International Journal of Microwave and Optical Technology, vol. 13, no. 5, pp. 393-400, September 2018.

[19] N. Hassan, Z. Zakaria, W. Y. Sam, I. N. M. Hanapiah, A. N. Mohamad, A. F. Roslan, et al., "Design of dual-band microstrip patch antenna with right-angle triangular aperture slot for energy transfer application," International Journal of RF and Microwave Computer-Aided Engineering, vol. 29, no. 1, pp. 1-11, January 2019.

[20] B. Anantha and R. S. R. Gosula, "Compact single feed dual band microstrip patch antenna with adjustable dual circular polarization,” IETE Journal of Research, pp. 1-9, April 2019.

[21] S. J. Shi and W. P. Ding, "Radiation pattern reconfigurable microstrip antenna for WiMAX application," Electronics Letters, vol. 51, no. 9, pp. 662-664, April 2015.

[22] I. J. Bahl and P. Bhartia, Microstrip antennas, 2nd ed. USA: Artech House, 1980.

Copyright $($ by the authors. Licensee TAETI, Taiwan. This article is an open access article distributed under the terms and conditions of the Creative Commons Attribution (CC BY-NC) license (https://creativecommons.org/licenses/by-nc/4.0/). 